\title{
Delayed Allergic Cutaneous Hypersensitivity to Icodextrin
}

\author{
By Nikesh Adunuri MD and Saira Zafar MD FRCPC
}

\begin{abstract}
About the Authors
Nikesh Adunuri is with the Department of Internal Medicine at the University of Western Ontario. Saira Zafar is with the Department of Internal Medicine at the University of Western Ontario.
\end{abstract}

Submitted: March 18, 2017. Accepted May 7, 2017. Published December 29, 2017.

\begin{abstract}
Rashes pose a unique challenge to general internists. Here we present a case of a 51-year-old female with end-stage renal disease (ESRD) on peritoneal dialysis who presented to a General Internal Medicine clinic with a vesiculobullous rash on palms and soles 6 months after using icodextrin dialysate, a widely used osmotic agent in peritoneal dialysis. The investigations were positive for an elevated eosinophil count, elevated IgE level and a skin biopsy consistent with an allergic reaction. Her symptoms and labs normalized after stopping icodextrin. There are some reports of allergic reactions to icodextrin which usually occur within a month of initiation of the agent and are self-limiting. Here we hope to report a case of a reaction that occurred 6 months after using icodextrin.
\end{abstract}

\begin{abstract}
Résumé
Les éruptions cutanées posent un défi particulier aux internistes généraux. Nous rapportons ici le cas d'une femme de 51 ans atteinte d'insuffisance rénale terminale (IRT), sous dialyse péritonéale, qui se présente à une clinique de médecine interne générale avec une éruption cutanée vésiculo-bulleuse sur les paumes et la plante des pieds. Depuis six mois, la patiente utilise un dialysat d'icodextrine, un agent osmotique largement utilisé en dialyse péritonéale. Les analyses ont révélé une numération élevée des éosinophiles, un taux élevé d’IgE et une biopsie cutanée a indiqué la présence d'une réaction allergique. Les symptômes et les résultats d'analyses se sont normalisés après l'arrêt de l'icodextrine. Des réactions d'allergie à l'icodextrine ont déjà été rapportées, mais celles-ci surgissent habituellement dans le mois suivant le début de l'usage de l'agent et se résorbent d'elles-mêmes. Nous désirons signaler un cas de réaction survenue six mois après le début de l'utilisation de l'icodextrine.
\end{abstract}

Rashes can be an "itchy" problem in General Internal Medicine clinics (GIM). Given the complexity of patients seen at these clinics; identifying the true underlying unifying diagnoses can sometimes be a challenge. Here, we would like to present a case of a delayed cutaneous reaction to icodextrin, a relatively safe osmotic agent used widely in peritoneal dialysis. ${ }^{1,2}$ There are some reports of allergic reactions to icodextrin but they usually occur after initiation of the agent and is usually self-limiting. ${ }^{1-6}$
Here we present a case of a patient who presented to our GIM clinic with acute bullous lesions on palms and soles, 6 months after using icodextrin in her peritoneal dialysis.

\section{Case Presentation}

The patient is a 51-year-old female with end-stage renal disease (ESRD) on peritoneal dialysis who presented to a General Internal 
Medicine urgent clinic with a maculopapular rash on palms and soles progressing to vesiculobullous lesions.

The patient's past history is significant for ESRD secondary to renovascular disease and atrophic kidney who has been on peritoneal dialysis for the past two years. Her other comorbid conditions include hypertension (on telmisartan, amlodipine and bisoprolol), hypercholesterolemia (on atorvastatin), anemia (on darbepoetin alpha), endometriosis and migraines. Other medications include alendronate and sevelamer. None of these medications were new. She has allergies to dozasoxin and hydralazine which give her headaches but she hasn't been exposed to them recently. She has no pet or seasonal allergies.

She initially started noticing a maculopapular pruritic rash on her hands and feet. Initially the rash improved with over the counter antihistamines, however after a week later, the rash reoccurred on the palms and soles. The rash progressed into painful bullous lesions on her palms and soles (Figure 1). The trunk, oral mucosa and other parts of the body were spared. There no fevers or chills or arthralgia's or any constitutional symptoms. She denied any exogenous exposures such as farm, pets, travel, sick contacts, insect bites or household changes. Review of systems otherwise was quite unremarkable. She denied any previous history of dermatological issues. There were no obvious triggers according to her. No new medications were added.

After careful evaluation, it was noted that there was a change in her dialysate. She has been on PD dialysis since March 2014 and her PD dialysate was changed to icodextrin on December 2015. There were no acute issues with the change and she underwent PD runs without any hiccups. It was only until July 2016 when she had the rash outbreak as described above.
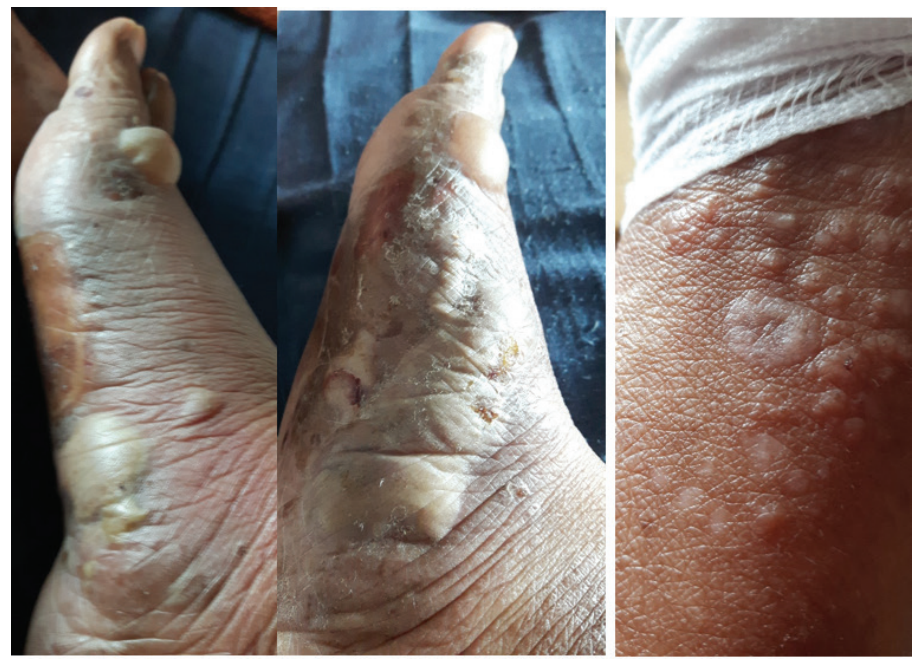

Figure 1. Skin lesion due to icodextrin (initial presentation).
The initial lab investigations showed an elevated white cell count at 15 with significant eosinophilia (2.9), elevated IgE level at 947 . Her anti-ASO titre was negative. Her electrolytes, liver function tests and rest of her lab tests were within normal limits.

A skin biopsy was undertaken in the clinic. Two skin-punch biopsies were taken from the forearms sized 0.4 by $0.3 \mathrm{~cm}$ and pathology results were consistent with an allergic reaction. The epidermis exhibited mild spongiosis (intercellular edema). A focal intra-epidermal vesicle is identified in the tissue biopsy for immunofluorescence. Rare eosinophils are identified in the epidermis. In the dermis there is a dense perivascular inflammatory infiltrate composed of lymphocytes, histiocytes and eosinophils. Stromal eosinophils are also identified. Special stains (PASd) for fungal organisms are negative. Viral cytopathic effects are not identified. Immunofluroescene staining for IgG, $\operatorname{IgA}$, IgM, fibrinogen and C3 were negative. In summary, there is a spongiotic dermatitis with intra-epidermal vesicle and eosinophils. The findings are consistent with a drug or allergic type reaction.

Given that the only change was the icodextrin dialysate, the etiology of her rash was deemed to be due to icodextrin. The nephrology team were notified and her dialysate bath was changed. Her rash has started to resolve with no new

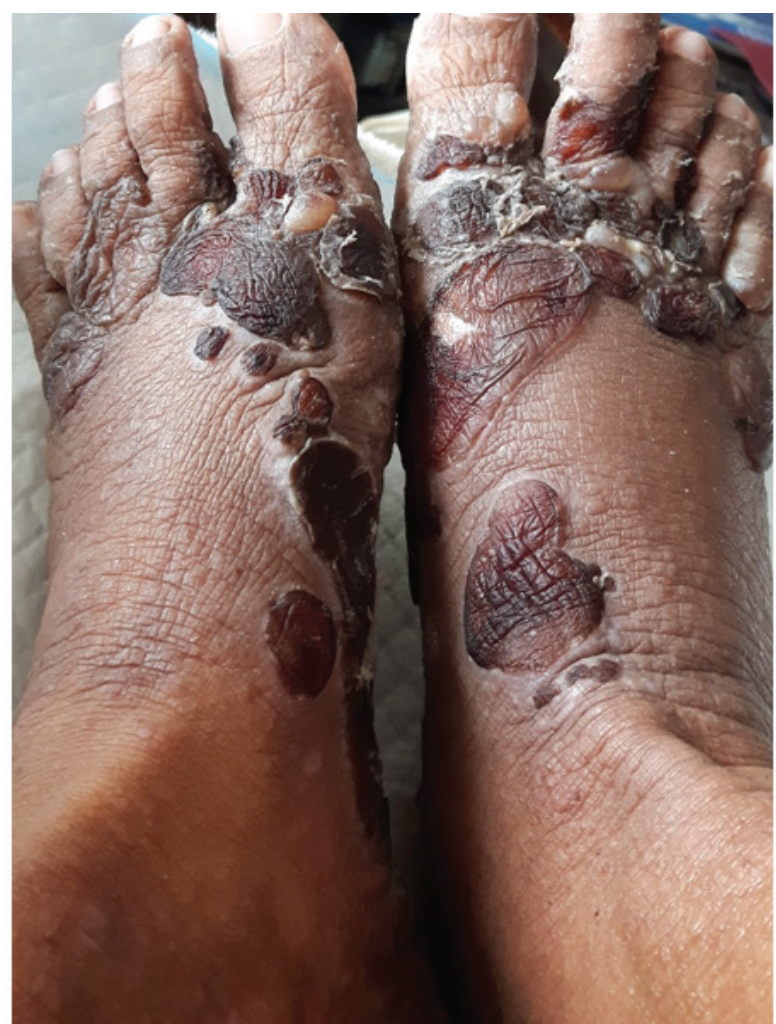

Figure 2. Slow resolution of the lesions upon discontinuation of icodextrin. 
bullous formations since the discontinuation of the icodextrin (Figure 2). Her laboratory showed resolution of eosinophilia and IgE elevation.

\section{DISCUSSION}

The differential diagnosis for a rash in a patient presenting to Internal Medicine is wide ranging from contact dermatitis, SLE rash, Toxic shock syndrome or erythema multiforme (precipitated either by drugs or infections such as Coxsackie, syphilis or parvovirus). Sometimes vesiculobullous lesions can present as primary immunological dermatological conditions such as Pemphigus. It's important to identify the cause as some conditions require urgent treatment with steroids. Here, we presented a case secondary to icodextrin dialysate which occurred 6 months into initiation of the dialysate. There have been cases described in the literature but a such a delayed reaction is something that has not been documented before so we feel it is something to consider in ESRD patients on PD that are seen in GIM clinics.

Icodextrin is a dextrin glucose polymer, which is used as osmotic agent in peritoneal dialysis due to its effective ultrafiltration, slow absorption leading to longer osmotic gradient and better diabetic control compared to glucose solution. ${ }^{1,7-10}$ It is generally well tolerated but there are few case reports of acute self-limiting allergic hypersensitivity reaction to icodextrin in the literature. ${ }^{1-7}$ The rashes seem to be vesicular or exofoliative eruptions on palms or trunk. The incidence of this seems to be around $10 \%$ based on few reports and most of them are selflimiting and start within a month of starting treatment. ${ }^{6-8}$ The biopsy of these skin rashes showed nonspecific inflammatory changes with rashes healing with discontinuation of icodextrin. In one randomized control trial maculopapular rashes were significantly higher in the icodextrin group compared to the $4.25 \%$ dextrose solution. ${ }^{7,8}$

The pathophysiology is unclear but is possibly triggered by immune sensitization of icodextrin by its metabolite (maltose) causing cutaneous reactions. ${ }^{1-4}$ Icodextrin is partially absorbed from the peritoneum via the peritoneal lymphatic drainage. ${ }^{8-10}$ Maltose, a metabolite of icodextrin, is structurally similar to dextran which is used as a plasma expander, is also known to cause allergic reactions in studies. ${ }^{1}$ The two polymers differ in their linkage of glucose molecules, $\alpha-1,4$ for icodextrin and a-1,6 for dextran and dextran antibodies have been reported in PD patients. ${ }^{1}$ It is plausible that these immune complex could potentially be triggering a delayed cutaneous reaction in patients. ${ }^{9,10}$ There is, however, no known icodextrin epitope responsible for allergic reactions. ${ }^{10}$ The delayed skin reaction might share a common pathway with persistent pruritus seen with similar compounds like hydroxyethyl starch (HES) infusion, which is used as an intravascular volume expander. ${ }^{11}$ Immunoelectron microscopic evaluation of skin biopsies in patients with pruritus after exposure to HES showed vacuolization and deposition in Schwann cells, endoneural and perineural cells. ${ }^{11}$ Tissue accumulation in a dose-dependent fashion might explain the delayed skin reactions seen with these structurally similar molecules and more research needs to be undertaken to better elucidate the underlying pathophysiology.

Our patient is unique in that she presented almost six months into the initiation of icodextrin dialysate with vesicular and bullous eruptions on her hands and palms sparing the rest of her body. It is important to consider this a possibility even after months of starting the dialysate.

\section{References}

1. Lam-Po-Tang MKL, Bending MR, Kwan JTC: Icodextrin hypersensitivity in a CAPD patient. Peritoneal Dial Int 1997;17:82-84.

2. Ankur G, Mohan B. Icodextrin and skin rash: Unusual presentation. Indian J Nephrol 2012; 22:62-3.

3. Fletcher S, Stables G, and Turney JH. Icodextrin allergy in a peritoneal dialysis patient. Nephrol Dial Transplant 1998;13:2656-58.

4. Cevher SK, Ozkayar N and Dede F. A case report on allergic rash caused by icodextrin. Case Rep Nephrol Dial 2015;5:26-29

5. Wilkie ME, Plant MJ, Edwards L, Brown CB: Icodextrin 7.5\% dialysate solution (glucose polymer) in patients with ultrafiltration failure: extension of CAPD technique survival. Peritoneal Dial Int 1997;17:84-86.

6. Goldsmith D, Jayawardene S, Sabharwal N, Cooney K: Allergic reactions to the polymeric glucose-based peritoneal dialysis fluid icodextrin in patients with renal failure. Lancet 2000;355:897.

7. Finkelstein F, Healy H, Abu-Alfa A, et al: Superiority of icodextrin compared with $4.25 \%$ dextrose for peritoneal ultrafiltration. J Am Soc Nephrol 2005;16:546-554.

8. Almiani M and Kohn OF. Severe exfoliative skin rash with icodextrin. Kidney Int 2014;86:449.

9. Aanen MC, de Waart DR, Williams PF, Out TA, Zweers MM, Krediet RT. Dextran antibodies in peritoneal dialysis patients treated with icodextrin. Perit Dial Int 2002;22:513-5.

10. Silver SA, Harel Z and Perl J. Practical considerations when prescribing icodextrin: a narrative review. Am J Nephrol 2014;39:515-27

11. Metze D, Reimann S, Szepfalusi Z, et al. Persistent pruritus after hydroxyethyl starch infusion therapy: a result of long-term storage in cutaneous nerves. $\mathrm{Br}$ J Dermatol 1997;36(4):553-59.

Author Disclosure: None. No external funding. Patient consented for pictures submitted. 